\title{
Association Between Walking Speed and Urinary Incontinence in the Older Women Which Patients Should Be Referred to Geriatricians?
}

\author{
Volkan ATMIS', Basak GULER ${ }^{2}$ \\ Ankara, Turkey
}

ABSTRACT

OBJECTIVE: Primary end-point of this study was to detect if there is an association between walking speed and urinary incontinence in older women and secondarily to detect an association between urinary incontinence with other geriatric syndromes.

STUDY DESIGN: This is a prospective and cross-sectional study. Three hundred and eighty-nine old aged women admitted to the Geriatrics Department of Ankara University were enrolled and urinary incontinence and type of urinary incontinence, Handgrip strength test, Timed up and Go test, Katz Index of Independence in Activities of Daily Living, Lawton Index of Instrumental Activities of Daily Living, Mini Nutritional Assessment, Mini-Mental State Evaluation, Geriatric Depression Scale, Body Mass Index $(\mathrm{BMI})$ of these participants were recorded. Association of urinary incontinence and these parameters were analyzed.

RESULTS: The median age of the study population was 68 (58-86 years of age). Two hundred and fiftyeight (66.32\%) had hypertension, $122(31.36 \%)$ had diabetes mellitus, 51 (13.11\%) had asthma/Chronic obstructive lung disease, $49(12.59 \%)$ had coronary artery disease and $9(2.31 \%)$ had cerebrovascular disease. One hundred and seventy-eight (45.7\%) patients had urinary incontinence (88 urge, 55 stress, 35 mixed). One hundred and eight $(27.76 \%)$ of patients had Mini-Mental State Evaluation score $\leq 23$. Patients with urinary incontinence detected to have a longer duration of Timed Up and Go test, higher Geriatric Depression Scale score and BMI with p-values $0.005,0.004$, and $<0.01$ respectively; and lower Activities of Daily Living (Katz-Activities of Daily Living) score with a p-value of $<0.01$ results. Mini-Mental State Evaluation and Mini Nutritional Assessment scores were not statistically different between the continent and incontinent group.

CONCLUSION: Whenever urinary incontinence is detected in an older woman, geriatrician referral should be considered since urinary incontinence is associated with decreased walking speed, Handgrip strength test, Activities of Daily Living, Instrumental Activities of Daily Living or increased Geriatric Depression Scale; any of which is a symptom or result of at least one geriatric syndrome.

Keywords: Geriatric syndrome, Older women, Urinary incontinence, Walking speed

Gynecol Obstet Reprod Med 2020;26(1):44-50

\section{Introduction}

Urinary incontinence (UI) is the involuntary loss of urine and may have multiple etiologies (1). $15-30 \%$ of older adults suffer from UI, and half of them show the signs on a daily to

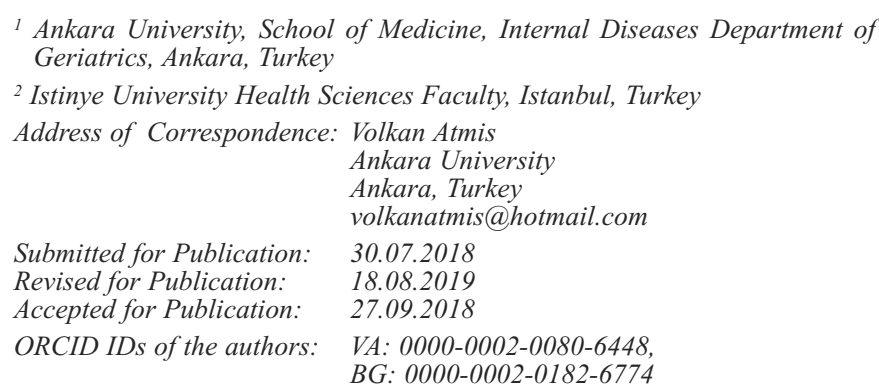

\begin{tabular}{|c|c|}
\hline \multirow{3}{*}{ 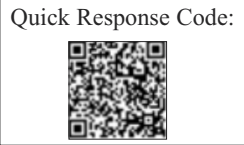 } & Access this article online \\
\hline & $\begin{array}{l}\text { Website: www.gorm.com.tr } \\
\text { e- mail: info@gorm.com.tr }\end{array}$ \\
\hline & DOI:10.21613/GORM.2019.1019 \\
\hline
\end{tabular}

How to cite this article: Atmis V. and Guler B. Association Between Walking Speed and Urinary Incontinence in the Older Women Which Patients Should be Referred to Geriatricians? Gynecol Obstet Reprod Med 2020;26(1):44-50 weekly basis (2). Up to $77 \%$ of old women experience UI, with subtypes of stress, urgency, mixed and overflow (3). UI causes physical and psychological issues and a decrease in the quality of life $(4,5)$. It also results in an economic burden as much as 10 billion dollars annually. In the United States, women with urinary incontinence pay up to 900 dollars annually for routine care of UI $(6,7)$.

Aging and geriatric syndromes like functional disability and cognitive impairment are risk factors for UI (8). UI is related to frailty, increased risk of falls, fractures, and death in the old age group (9-11). In the elderly, UI, also is associated with increased caregiver burden, depression, anxiety, and social isolation. As the world's population ages, the importance of defining common health problems of the elderly and finding managing strategies for them increases.

Firstly, UI may have common pathophysiological mechanisms with geriatric syndromes ; functional disability, cognitive impairment, frailty, falls. Secondly, its risk may be in- 
creased with these comorbid conditions; restricted mobility or dexterity, irritant exposure, potential drug side effects. And thirdly, UI may be a symptom or complication of an underlying disease; polyuria, infectious diseases, stool impaction or constipation, atrophic urethritis or vaginitis. So, clinicians should also consider UI as a symptom of an underlying disease.

Gait speed is a tool that is reported to predict functional decline and mortality among old aged patients alone from nine selected cohorts (12). It is a part of the comprehensive geriatric assessment, in clinical practice, it helps in identifying patients who need further evaluation for geriatric syndromes such as falls, dementia, etc. Patients with $<0.8$ meters/second speed are more likely for fall, frailty, and survival. Gait speed and bladder control are found to be associated in some research and other researchers suggested using walking speed may be an effective tool for early detection of geriatric syndromes like UI $(13,14)$.

Although UI is detected to be related to geriatric syndromes, there are a limited number of studies in literature analyzing the relationship between walking speed of the elderly women and UI, and other geriatric syndromes. In this study, our primary end-point was to detect if there is an association between walking speed and UI in older women and secondarily to detect an association between UI with other geriatric syndromes.

\section{Material and Method}

The study was conducted in the polyclinics of Geriatrics Unit of Ankara University. Every woman admitted to Geriatrics unit were evaluated for enrolling into the study. Patients were excluded from the study if they have advanced dementia, not accepted to participate in the survey, has acute incontinence, or cannot communicate. Patients with acute/reversible incontinence were detected according to DIAPPERS where D: Delirium, I: Infection, A: Atrophic vaginitis/urethritis, P: Pharmacologic agents, P: Psychiatric (Psychosis, etc.), E: Endocrine causes (hyperglycemia, hypercalcemia, etc.), and R: Restricted Motility (15). Four hundred eighty-nine patients were included in the study; 45 patients who did not want to participate, 23 patients with advanced dementia, 18 patients with acute incontinence and 14 patients who had difficulty in communication were excluded from the study, and the study was conducted with 389 females. Excluding seven patients 56-59 years of age, all patients were $>60$ years of age, the oldest patient as 87 years old. Participants were divided into two groups, 178 participants with urinary incontinence and 211 participants without urinary incontinence. Demographic characteristics of all patients were recorded. Handgrip strength test (HGST), Timed up and Go test, Katz Index of Independence in Activities of Daily Living (ADL), Lawton Index of Instrumental Activities of Daily Living (IADL), Mini Nutritional Assessment (MNA), Mini-Mental State
Evaluation (MMSE), Geriatric Depression Scale (GDS), Body Mass Index (BMI), Hospitalization and Fall histories in the last year of each participant were recorded.

Hand Grip Strength was detected by Takei Hand Grip dynamometer, calibrated a month before the study. Timed up and go test determines fall and risk and measure the progress of balance, sit to stand and walk. Patients started in a seated position, upon command walked three meters, turned around, walked back to the chair and sit down. Time of the patient to complete this task is recorded in seconds.

Activities of Daily Living ranks the adequacy of bathing, dressing, toileting, transferring, continence, and feeding of the patient. Every task is either zero or one point. Patients are dependent for ADLs if they have zero scoring and independent if they have six points. IADL ranks the adequacy of ability to use the phone, shopping, food preparation, housekeeping, laundry, transportation, the responsibility of medication and ability to handle finances. Every task is either zero or one point. Patients are dependent in IADLs if they have zero-point scoring and independent if they have eight points scoring.

Mini Nutritional Assessment is a tool for detecting the nutritional status of the patients. Malnutrition is with scores $<17$, and the maximum score is 30 . MMSE is a tool for detecting the cognitive ability of the patient. The maximum score is 30 and $<24$ points is associated with cognitive impairment. The test examines the patient's orientation, registration, attention and calculation, recall, language, repetition and complex commands. GDS is for screening depression. It has 15 questions with zero or one point each. Scores $>$ five suggests depression. UI and UI type is detected with a questionnaire of three questions offered by Brown et al. (16) (Form 1). OpenEpi program offered by Centers were disease control was used for detecting participant number.

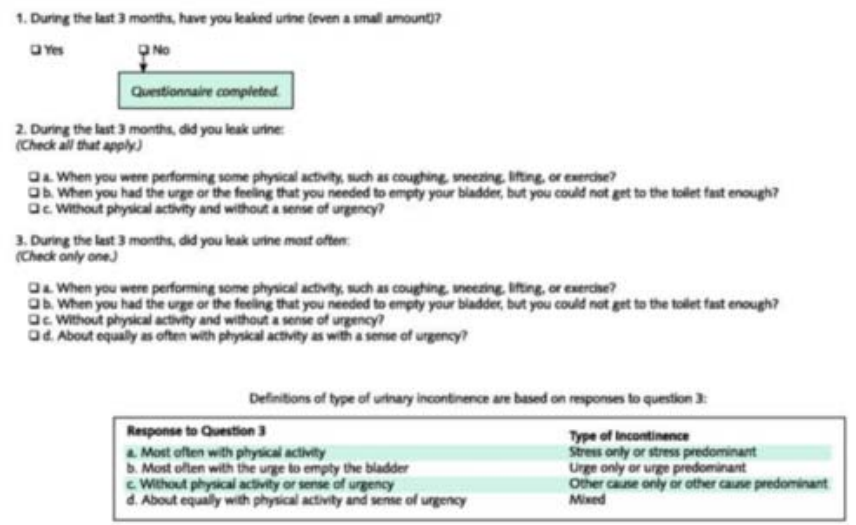

Geriatric assessment of every patient was performed by a geriatrician. Ethical approval is from Ankara University Ethical committee with number: 11-747-18, date: 25.6.2018. This is a prospective study. Informed consent is obtained from every patient. We conducted this study in compliance with the principles of the Declaration of Helsinki. 
The acquired data was used for descriptive analysis. Continuous variables were evaluated for normality of distribution by visual and analytic methods. Comparisons between the groups were performed via the Mann-Whitney U Test, and categoric variables were compared by Chi-Square test. A pvalue lesser than 0.05 was considered as statistically significant. Statistical analyses were performed using SPSS v23.0 (IBM Corp. Released in 2015. IBM SPSS Statistics for Windows, Version 22.0 Armonk, NY: IBM Corp.).

\section{Results}

A total of 389 patients were included in the study. The demographic parameters were demonstrated in table I. A hundred and seventy-eight (45.7\%) patients had UI. $22.6 \%$ of the total patients had urge incontinence; $14.1 \%$ had stress incontinence, and $8.9 \%$ had a mixed type. The median age of the study population was $68.258(66.32 \%)$ had hypertension, 122 (31.36\%) had diabetes mellitus, 51 (13.11\%) had asthma/ chronic obstructive lung disease, 49 (12.59\%) had coronary artery disease and $9(2.31 \%)$ had cerebrovascular disease.

Table I: Characteristics and geriatric evaluations of the patients

\begin{tabular}{lc}
\hline Parameter & $\begin{array}{c}\text { Median } \\
\text { (number and rate of event) }\end{array}$ \\
\hline Urinary Incontinence & (n) \\
Urge Incontinence & $88(22.6 \%)$ \\
Stress Incontinence & $55(14.1 \%)$ \\
Mixed Incontinence & $35(8.9 \%)$ \\
\hline
\end{tabular}

$¥:$ Number and rate of event

The comparison of geriatric assessment parameters with UI was demonstrated in table II. The group having UI had sig- nificantly higher scores in Timed up and go test when compared to the continent group ( $p=0.005)$. Despite similar median range values in both groups, analysis regarding interquartile ranges and confidence intervals revealed significantly higher Katz scores in the continent group $(p<0.01)$.

As expected, BMI and GDS were significantly higher in the group suffering UI ( $p<0.01, p=0.004$, respectively).

The patients of the two groups did not differ in age, MMSE and MNA scores. No significant difference was observed when the continent and incontinent groups were compared in terms of falls and hospitalization, in the previous year ( $p=0.886$ and $p=0.338$, respectively) (Table III). Also, there was no statistically significant difference between walking speed and urinary incontinence subtypes.

\section{Discussion}

In this study, we aimed to detect if there is an association between walking speed and UI in older women and secondarily to detect an association between UI with other geriatric syndromes. According to our results, we detected that walking speed is diminished among old women with UI and also women with urinary continence were detected to have increased frequency of dementia, increased functional limitation and dependency and not surprisingly increased BMI.

In geriatric practice, the gynecological referral is requested whenever pelvic pain, recurrent urinary tract infection, hematuria, pelvic organ prolapse, pelvic surgery or radiation history accompanies UI, or when overflow incontinence is suspected. In general, our study results show that similarly to geriatric practice, in gynecological practice geriatric referral seems to

Table II: Comparison of geriatric assessment parameters between incontinent and continent women

\begin{tabular}{|c|c|c|c|}
\hline & Incontinent group & Continent group & $p$ value \\
\hline $\mathrm{Age}^{\ddagger}$ & $68(59-86)$ & $67(58-85)$ & 0.210 \\
\hline Number of living child ${ }^{\ddagger}$ & $3(0-9)$ & $3(0-10)$ & $0.025^{*}$ \\
\hline Hand grip strength ${ }^{\ddagger}$ & $19.5(0-45)$ & $20.3(8-32.40)$ & 0.400 \\
\hline Timed up and go test ${ }^{\ddagger}$ & $8.1(3-29)$ & $6(3-20)$ & $0.005^{*}$ \\
\hline Katz ${ }^{\ddagger}$ & $6(1-6)$ & $6(1-6)$ & $<0.01^{*}$ \\
\hline Lawton ${ }^{\ddagger}$ & $8(4-8)$ & $8(3-8)$ & 0.387 \\
\hline Mini nutritional assessment ${ }^{*}$ & $13(10-14)$ & $13(9-14)$ & 0.781 \\
\hline Minimental score ${ }^{\ddagger}$ & $26(12-30)$ & $26(10-30)$ & 0.351 \\
\hline Geriatric depression scale & $5.5(0-15)$ & $4(0-14)$ & $0.004^{*}$ \\
\hline Body mass index & $33.7(23.35-66.67)$ & $31.5(20.82-55.03)$ & $<0.01^{*}$ \\
\hline
\end{tabular}

${ }^{*} p$-value $<0.05$ is accepted statistically significant. Despite similar median range values in both groups, analysis regarding interquartile ranges and confidence intervals revealed significantly higher KATZ scores in the continent group.

Table III: Comparison of continent and incontinent women in terms of history of hospitalization and fall

\begin{tabular}{lccc}
\hline & Incontinent Group & Continent Group & $p$ value \\
\hline Hospitalization in Last Year & $25(14.1 \%)$ & $37(17.6 \%)$ & 0.338 \\
Fall in Last Year & $52(29.2 \%)$ & $60(28.4 \%)$ & 0.886 \\
\hline
\end{tabular}


be needed or at least should be taken into consideration whenever an elderly woman with UI admits to gynecology clinics.

UI is a frequent problem among older women. It is reported that $50 \%$ of institutionalized older people and $15 \%$ of community-dwelling elderly individuals have UI (10). In general, UI is reported to be between 5-72\% among women, depending on the selected population and different methods of studies (17). Kasikci et al. reported $51.6 \% \mathrm{UI}$ in his research among elderly Turkish women $(18,19)$. We observed similar UI prevalence rates in our study, which was $45.7 \%$. We believe that this study result is representative of Turkish older women.

Age and parity are found to be correlated with UI (20). Our groups with and without UI had a similar median age. Although the median values for the parity were three for both groups, analysis regarding interquartile ranges and confidence intervals revealed that increased parity is associated with increased frequency of UI. Change in the anatomic support of the pelvic floor, and obstetric trauma are accused of UI (20). Although, age and parity are non-modifiable risk factors for UI, these data in clinical history may help clinicians in the differential diagnosis of reversible vs persistent causes of UI. This result also favors clinicians for positive discrimination towards women with older age and multiparity on questioning for UI independent from admission complaint. Since, UI complaint can be missed in clinical practice secondary to patient dependent causes (embarrassment, belief that UI is a normal part of aging or cognitive impairments) or polyclinic based circumstances (limited time for examination, etc.), clinicians should set a proper environment and attitude for UI questioning. Recently, Sönmez et al. also concluded in their study that $67 \%$ of UI patients do not have help-seeking behavior (21).

Obesity increases UI risk via increased intraabdominal pressure and physical difficulty in reaching the toilet $(22,23)$. The group suffering UI in our study had significantly higher BMI when compared. Obesity although is reported to be probably protective against mortality in this age group, it is a modifiable risk factor that can reverse UI also in old age group (2426). Especially for stress UI, no pharmacologic treatment is approved by the FDA, and up to $50 \%$ of decrease in UI is reported by weight loss in this group (27). So, lifestyle modification should be tried first in this age group before any medication since anticholinergics increases dementia and delirium risk, especially in the old age group.

Longer durations in Timed up and go test was observed in patients with UI in our study, which was consistent with the study of Murukesu et al. (28). As the duration prolongs, it is obvious that the time reaching the toilet lengthens UI risk increases. But test durations were found to be extended in all types of UI, including stress incontinence, which is independent of the reaching time to the toilet. In this study, we observed that HGS score has a lower median value in the UI group, but this difference was not statistically significant. We suggest that low HGS may be representative of decreased muscle strength also in pelvic architecture, which is more related to voluntary muscles of voiding, but further studies are needed. Similarly, Kang et al. observed that UI was associated with grip strength and history of falls (29). As frailty related factors increases, UI frequency also increases. The predictive value of frailty on UI was also observed by Chong et al. (30). They found the predictive power of frailty on incident UI even after 12 months from hospital discharge. Lee et al. detected that UI is associated with walking speed rather than the muscle mass (31). Our study shows that walking speed besides being essential for elderly health is also associated with UI. In subgroup analysis, this test is detected to be associated with all types of UI. So, whenever UI is detected in gynecological admission of any old aged woman, geriatric referral should be a part of clinical examination. Sarcopenia, age-related loss of skeletal muscle mass, strength and function have 5-33\% frequency rate among older women (32,33). Pelvic architecture also has its muscle mass and Lee at al. speculated that this might also be lost among sarcopenic elderly and muscle quality rather than its mass is an independent risk factor for UI (31). So, whenever UI is present in an elderly, it may be a symptom, rather than a disease itself, of a more generalized geriatric syndrome.

Urinary incontinence is recorded to be associated with geriatric syndromes especially polypharmacy, delirium, fecal incontinence, depression, and decreased gait speed. In addition, UI whenever with decreased gait speed is furthermore associated with falls and decreased survival (34). Hypertension is also reported to result in increased mortality only in patients with decreased walking speed (35). So, whenever urinary UI is detected in the old aged group if walking speed is also decreased, geriatric evaluation may result in detection of related geriatric syndromes which will increase in survival of patients, increase in quality of life, reduce polypharmacy, decrease falls and fall-related fractures, and decrease delirium incidence. In addition, anticholinergic drugs used for the treatment of UI, frequently results in decline in functional status, increase in delirium and dementia, increase in falls and depression and most important of all increase in mortality by its mechanism of action, so before starting drug treatment, geriatrician referral might help in excluding or detection of geriatric syndromes which is essential especially UI is a symptom or complication of an underlying geriatric syndrome (36-38). Lastly, most recently, an article was published in JAMA, with 3.5 million individuals of up to 20 years of follow up. It was reported that anti-muscarinics were found to be associated with dementia especially whenever started before 80 years of age, since the mean age of our study is 68 , our group seems to be among patients under dementia with anti-muscarinic use. And authors mentioned to be careful about adverse effects and use alternative non-pharmacological treatment methods whenever possible for depression, alternative drugs without anticholinergic effect for Parkinson and bladder training (39). Since bladder training also needs voluntary muscles, walking 
speed might be helpful in estimating which old aged patient group would benefit from bladder training, but further studies are needed to say that.

The Katz score of the patients with UI was significantly lower in our study. Timmermans et al. also found a reverse association between the Katz score and UI (40). Transportation, toileting, and continence are among the components of the Katz score helpful in determining the dependence of elderly in activities mainly in the household. From this perspective, it must be kept in mind that any older women with UI in gynecologic practice may be dependent on her activities and clinical decision making of the patient should include this data since complex treatment regimens probably will not be feasible for the patients.

We detected higher scores in GDS of patients with UI which may be due to social withdrawal, fear of stigmatization, embarrassment, and low self- esteem which is frequently detected in the literature $(28,41,42)$. Poor sleep quality due to incontinence because of enuresis or nocturia may also lead to depressive symptoms. So, whenever a patient with UI admits, depression, sleep disorders, and anxiety is always a probability. Before starting treatment for depression with medications or referral, UI should be treated first. Since polypharmacy is among frequent geriatric syndromes with increased costs and mortality, benefits and harms of depression therapy should be weighed (43-44).

We did not observe any significant effect of UI on neither the fall rates nor the rate of hospitalization in the previous year, in our study. Although there are studies reporting a correlation of UI with increased risk of falls, a recent study by Agudelo-Botero, et al. conducted on 598 older adults found no evidence on UI and its link to recurrent falls $(9,45)$. They speculated in this study that factors affecting functional levels and functionality of the elderly may be common for falls and UI, and UI is not responsible for most of the falls rather it is a symptom alerting that patient has increased fall risk, and they offered future investigations for fall risk for patients with UI. In our study we recorded falls in the last year but in many other studies fall history of two years are recorded, and UI seems to be more related to recurrent falls rather than occasional falls, and in this study, most of the falls are occasional since $>90 \%$ of patients in our study fell once.

This study is gender and age-specific, prospective study. Demographic characteristics of the patient groups are similar, which decreases confounder risk. In addition, this is among the limited number of studies analyzing UI and gait speed association, which is our primary end-point. These are strong parts of our study. We detected UI according to incontinence questionnaire which has nearly $75 \%$ sensitivity and specificity for urge incontinence and $86 \%$ and $60 \%$ sensitivity and specificity, respectively for stress incontinence which is the weak part of our study.

\section{Conclusion}

Since UI has nearly 50\% frequency among old aged woman, every geriatric women should be questioned about UI independent of her application complaint. And, whenever UI is detected in an older woman, geriatrician referral should be considered since UI is associated with decreased walking speed, HGST, ADL, IADL or increased GDS; any of which is a symptom or result of at least one geriatric syndrome.

Acknowledgement: None

Conflict of interest: Authors of this study declare that they have no conflict of interest.

Funding: There was no funding for this study

Contributions of the Authors: VA and BG have contributed in concept, design, control and supervision, data collection and processing, analysis and interpretation, literature review, writing, critical review and references of this article.

\section{References}

1. Goforth J, Langaker M. Urinary incontinence in women. N C Med J. 2016;77(6):423-5.

2. Resnick NM. Urinary incontinence in older adults. Hosp Pract. 1992;27(10):139-84.

3. Lukacz ES, Santiago-Lastra Y, Albo ME, Brubaker L. Urinary incontinence in women: a review. JAMA. 2017;318(16):1592-604.

4. Atmıs V, Aras S. Yaşlıda kontinansın değerlendirilmesi. T Klin Geriatr Spec Top. 2018;4(3): 46-55.

5. Sohn K, Lee CK, Shin J, Lee J. . Association between female urinary incontinence and geriatric health problems: results from Korean longitudinal study of aging (2006). Korean J Fam Med. 2018;39(1):10-4.

6. McCormick KA, Palmer MH. Urinary incontinence in older adults. Annu Rev Nurs Res. 1992;10:25-53.

7. Subak LL, Brown JS, Kraus SR, Brubaker L, Lin F, Richter HE, et al. The "Costs" of Urinary Incontinence for Women. Obstet Gynecol. 2006;107(4):908-16.

8. Inouye SK, Studenski S, Tinetti ME, Kuchel GA. Geriatric syndromes: clinical, research, and policy implications of a core geriatric concept. J Am Geriatr Soc. 2007;55(5):780-91.

9. Dokuzlar O, Koc Okudur S, Smith L, Soysal P, Yavuz I, Aydin AE, et al. Assessment of factors that increase risk of falling in older women by four different clinical methods. Aging Clin Exp Res. 2019.

10. Silay K, Akinci S, Ulas A, Yalcin A, Silay YS, Akinci MB, et al. Occult urinary incontinence in elderly women and its association with geriatric condition. Eur Rev Med Pharmacol Sci. 2016;20(3):447-51.

11. John G, Bardini C, Combescure C, Dallenbach P. Urinary incontinence as a predictor of death: a systematic review and meta-analysis. PLoS One. 2016;11(7):e0158992. 
12. Studenski S, Perera S, Patel K, Rosano C, Faulkner K, Inzitari $\mathrm{M}$, et al. Gait speed and survival in older adults. JAMA. 2011;305(1):50-8.

13. Booth J, Paul L, Rafferty D, Macinnes C. The relationship between urinary bladder control and gait in women. Neurourol Urodyn. 2013;32(1):43-7.

14. Kim H, Suzuki T, Yoshida H, Shimada H, Yamashiro Y, Sudo M, et al. Are gait parameters related to knee pain, urinary incontinence and a history of falls in communitydwelling elderly women? Nihon Ronen Igakkai Zasshi. 2013;50(4):528-35.

15. In geriatric urinary incontinence, think DIAPPERS mnemonic [Internet]. August 24, 2018. Available from: https://www.mdedge.com/internalmedicine/article/173368/geriatrics/geriatric-urinary-incontinencethink-diapers-mnemonic.

16. Brown JS, Bradley CS, Subak LL, Richter HE, Kraus SR, Brubaker L, et al. The Sensitivity and Specificity of a Simple Test To Distinguish between Urge and Stress Urinary Incontinence. Ann Intern Med. 2006;144(10): 715-23.

17. Aoki Y, Brown HW, Brubaker L, Cornu JN, Daly JO, Cartwright R. Urinary incontinence in women. Nat Rev Dis Primers. 2017;3:17042.

18. Kaşıkçı M, Kılıç D, Avşar G, Şirin M. Prevalence of urinary incontinence in older Turkish women, risk factors, and effect on activities of daily living. Arch Gerontol Geriatr. 2015;61(2):217-23.

19. Gibson W, Wagg A. New horizons: urinary incontinence in older people. Age Ageing. 2014;43(2):157-63.

20. Hallock JL, Handa VL. The epidemiology of pelvic floor disorders and childbirth: an update. Obstet Gynecol Clin North Am. 2016;43(1):1-13.

21. Sonmez S, Eraydin E, Arican Y, Sonmez F. Factors associated with help seeking behavior of Turkish women with urinary incontinence; a single center cross-sectional study. Gynecol Obstet Reprod Med. 2017;23(3):153-7.

22. Nihira MA, Henderson N. Epidemiology of urinary incontinence in women. Curr Womens Health Rep. 2003;3(4):340-7.

23. Townsend MK, Curhan GC, Resnick NM, Grodstein F. BMI, waist circumference, and incident urinary incontinence in older women. Obesity (Silver Spring). 2008; 16(4):881-6.

24. Atmis V, Gumussoy M. Yaşlı diyabetiklerde antropometrik ölçümler ile viseral yağ kalınlığı arasındaki ilişki. In: Demirkazık A, ed. İç Hastalıkları Güncellemesi 2019; Ankara: Ankara University Medical Faculty, 2019;11-22.

25. Demirbas B, Gur G, Simsek M, Bahsi R, Kosar P, Usta BM.Visceral obesity may have different effects on metabolic syndrome parameters in women and men. Acta Med Mediterran. 2016;32(1):45-50.
26. Dennis H. Sullivan LEJ. Nutrition and Obesity. In:Halter JB, Ouslander JG, Studenski S, High KP, Asthana S, Woolard N, et al, editors. Hazzard's Geriatric Medicine and Gerontology. New York: McGraw-Hill Education; 2017, p. 487-509.

27. Subak LL, Whitcomb E, Shen H, Saxton J, Vittinghoff E, Brown JS. Weight loss: a novel and effective treatment for urinary incontinence. J Urol. 2005;174(1):190-5.

28. Murukesu RR, Singh DKA, Shahar S. Urinary incontinence among urban and rural community dwelling older women: prevalence, risk factors and quality of life. BMC Public Health. 2019;19(Suppl 4):529.

29. Kang J, Kim C. Association between urinary incontinence and physical frailty in Korea. Australas J Ageing. 2018; 37(3):E104-E109.

30. Chong E, Chan M, Lim WS, Ding YY. Frailty Predicts Incident Urinary Incontinence Among Hospitalized Older Adults-A 1-Year Prospective Cohort Study. J Am Med Dir Assoc. 2018;19(5):422-7.

31. Lee WJ, Liu CY, Sun CC, Chen LK. Walking speed, not muscle mass, is associated with urinary incontinence in community-dwelling old Taiwanese. Neurourol Urodyn. 2016;35(8):1057-8.

32. Çağlar C. İleri yaşlı diyabetik hastalarda kas gücü ve fonksiyonunu korumada kan şekeri regülasyonun önemi. In: Demirkazık A, editor. İç Hastalıkları Güncellemesi. Ankara: Ankara University; 2019;17-22.

33. Shafiee G, Keshtkar A, Soltani A, Ahadi Z, Larijani B, Heshmat R. Prevalence of sarcopenia in the world: a systematic review and meta- analysis of general population studies. J Diabetes Metab Disord. 2017;16:21.

34. Kim KJ, Shin J, Choi J, Park JM, Park HK, Lee J, et al. Association of geriatric syndromes with urinary incontinence according to sex and urinary-incontinence-related quality of life in older inpatients: a cross-sectional study of an acute care hospital. Korean J Fam Med. 2019; 40(4):235-40.

35. Odden MC, Peralta CA, Haan MN, Covinsky KE. Rethinking the association of high blood pressure with mortality in elderly adults: the impact of frailty. Arch Intern Med. 2012;172(15):1162-8.

36. Green AR, Reifler LM, Bayliss EA, Weffald LA, Boyd $\mathrm{CM}$. Drugs contributing to anticholinergic burden and risk of fall or fall-related injury among older adults with mild cognitive impairment, dementia and multiple chronic conditions: a retrospective cohort study. Drugs Aging. 2019;36(3):289-97.

37. Corsonello A, Cozza A, D'Alia S, Onder G, Volpato S, Ruggiero $\mathrm{C}$, et al. The excess mortality risk associated with anticholinergic burden among older patients discharged from acute care hospital with depressive symptoms. Eur J Intern Med. 2019;61:69-74.

38. De Vreese LP, Mantesso U, De Bastiani E, Marangoni A, 
Weger E, Gomiero T. Anticholinergic burden in adult and elderly people with intellectual disabilities: Results from an Italian multicenter cross-sectional study. PLoS One. 2018;13(10):e0205897.

39. Coupland CAC, Hill T, Dening T, Morriss R, Moore M, Hippisley-Cox J. Anticholinergic drug exposure and the risk of dementia: a nested case-control study. JAMA Intern Med. 2019.

40. Timmermans L, Falez F, Melot C, Higuet S, Vincent D. Use of the International Consultation on Incontinence Questionnaire-Urinary Incontinence-Short Form (ICIQUI-SF) for an objective assessment of disability determination according to the Modified Katz Scale: a prospective longitudinal study. Minerva Urol Nefrol. 2016;68 (4):317-23.

41. Pahwa HS, Kumar A, Srivastava R, Kumar S, Goel A, Ahmad A. Partial penile amputation due to penile tourniquet syndrome in a child troubled with primary nocturnal enuresis - a rare emergency. Urology. 2013;81(3):653-4.

42. Kwon CS, Lee JH. Prevalence, risk factors, quality of life, and health-care seeking behaviors of female urinary incontinence: results from the $4^{\text {th }}$ Korean National Health and Nutrition Examination Survey VI (2007-2009). Int Neurourol J. 2014;18(1):31-6.

43. Varlı M, Bahşi R, Doğan Ş, Uysal H, Subaşı Ş, Toper M, et al. Nonprescription product use among geriatric outpatients. Ankara Med J. 2017;17(4):226-34.

44. Gumussoy M, Bahsi R. Proton pump inhibitors commonly used or abused in the elderly. $2^{\text {nd }}$ International $12^{\text {th }}$ Academical Geriatric Congress. 24-28.04.2019. Oral presentation. Antalya/Turkey

45. Agudelo-Botero M, Giraldo-Rodriguez L, MurilloGonzalez JC, Mino-Leon D, Cruz-Arenas E. Factors associated with occasional and recurrent falls in Mexican community-dwelling older people. PLoS One. 2018;13(2): e0192926. 